\title{
Lessons Learned from July 2012 Indian Blackout
}

\author{
Loi Lei Lai, FIEEE; Hao Tian Zhang, Student MIEEE; S. Mishra, Senior MIEEE; Deepak \\ Ramasubramanian Student MIEEE; Chun Sing Lai, Student MIEEE; Fang Yuan Xu, Student MIEEE
}

\begin{abstract}
Grid disturbances occurred on $30^{\text {th }}$ and $31^{\text {st }}$ of July 2012 leaving millions of Indians in the dark for hours. It was understood that in the blackout that occurred on $31^{\text {st }}$ of July, hydro power was slowed down which led to inadequate power generation while people overdrew more power for cooling off since the temperature was extremely high. This paper investigates the main reasons for the occurrence of the blackout. A simplified simulation model was established with DIgSILENT Power Factory to reproduce the grid behavior when the blackout occurred. After the sensitivity analysis, policy and strategies are recommended to enhance the grid security and robustness at the end of the paper.
\end{abstract}

Index Terms-Indian grid, DIgSILENT, Blackout, Strategic planning

\section{INTRODUCTION}

$\mathrm{T}$ wo extremely serious blackouts occurred in the Indian power grid in the end of July, 2012. Three of the Indian Grids were hit by power failure, leaving a huge disturbance in the country. The power outage affected 620 million people in India [1]. Trains were stopped, and a large amount of passengers were stranded on the platform. Traffic was congested in large cities including New Delhi and Kolkata due to failure of traffic lights. Government employees were told to go home as the Chief Minister claimed that power would be restored only 10 to 12 hours later [2]. It was claimed that the Prime Minister of India, Manmohan Singh urgently attended to attract $\$ 400$ million to invest in the grid and release the burden of electricity deficit, which is holding back economic growth [3]. Besides, India will import electricity from Tala, Bhutan to relieve the pressure by heavy loading [4]. Government of India has agreed to support Bhutan to develop hydro power and will purchase no less than $10000 \mathrm{MW}$ of the power from Bhutan by 2020 [5].

The first blackout occurred at around 2:35 am on the 30th of July in the Northern Region grid, which feeds electricity to 9 states of Northern India. Approximately 36,000 MW was affected in this blackout. Only $60 \%$ of load in the Northern

Loi Lei Lai, Hao Tian Zhang, Chun Sing Lai, Fang Xu are with State Grid Energy Research Institute, Beijing, China. Hao Tian Zhang and Chun Sing Lai are on leave from City University London, UK (Email: haotian.zhang.1@city.ac.uk) and Brunel University London, UK respectively.

Sukumar Mishra (Fellow of the Indian National Academy of Engineering) and Deepak Ramasubramanian are with Indian Institute of Technology Delhi.
Region was restored by 11:00 am by means of pumping electricity from hydro source in Bhutan and withdrawing

power from the Eastern and Western Region. The Northern Region grid was not supplied with the full load until 7:00pm. Afterwards, on 31 st of July, there was another disturbance which occurred at 1:00 pm, covering almost the entire power grid in India, involving the Northern Region, Eastern Region and Northeastern Region. Only a pocket Narora was not affected. There was about 48,000 MW of load affected in the second blackout, which was much more serious than the first one. It is reported that over 700 million people in India suffered from darkness and production slowdown due to electric power deficit. Some important loads like health services were affected $[6,7]$.

In fact, though the Indian grid has its rule on a rational tariff structure on power supply [8], relay mis-operation and incorrect setting, high loading due to high temperature and high reactive power consumption caused faults in the circuit. This has happened on several occasions over the past few years [9]. Plenty of media have reported the reasons for the blackouts. The Indian power minister, Sushilkumar Shinde, had 'suggested' that multiple states had overdrawn power from the grid [2]. The disturbance that occurred on 31st of July was also due to a weak monsoon which led to reduced output from the hydro generation plants [10]. This situation was aggravated due to the high summer temperatures which led to increased consumption of power [2]. Also, some experts blame the disturbance on the Indian grid infrastructure, which connects with both AC and DC transmission lines. The grids can exchange power with other regions flexibly only when DC transmission lines are connected between the regions during normal operation. In addition, the probability of spreading of faults in one region to other regions is very low. It may be that the Indian grid could not exploit the benefits of HVDC interconnection to maintain grid stability.

An Enquiry Committee has been founded to investigate the factors which led to the causes of the two grid disturbances and the report generated gave some critical recommendations [7]. One of the most serious problems is that the transmission system is very weak since the grid suffered from multiple outages. Besides, the Northern Region loads withdraw too much power from the Western Region grid thereby overloading the corridor linking the two regions. Ineffective dispatch cannot prevent the Northern part from over drawing electricity from the Western part. Without any fault occurring, 
the distance relay protecting the Bina-Gwalior link tripped under zone 3 conditions, thus causing the Western Region to separate from the Northern Region.

This paper will investigate the two disturbances and try to locate the main reasons for the occurrence of these two blackouts. A simple model is established with the DIgSILENT Power Factory environment [11], and some sensitivity analysis has been done to study the performance of entire grid. The strategy, policy and recommendations will be developed to reduce the blackouts from happening in the future.

\section{EVENTS DURING THE GRID DISTURBANCES}

Before the disturbance occurrence, Northern Region grid imported power from Eastern Region, Western Region and Northeastern Region. Besides, the Eastern region imported $1127 \mathrm{MW}$ from Bhutan, a country located to the northeast of India. The pre-disturbance generation and demand with power importing and exporting conditions are shown in Table 1. It is worthy noting that few lines were under maintenance few hours before the collapse happening [12].

Table 1. Generation and Demand Conditions with power import and export before disturbances

\begin{tabular}{|c|c|c|c|}
\hline Region & $\begin{array}{c}\text { Generation } \\
\text { (MW) }\end{array}$ & $\begin{array}{c}\text { Demand } \\
\text { (MW) }\end{array}$ & $\begin{array}{c}\text { Import } \\
\text { (MW) }\end{array}$ \\
\hline Northern & 32636 & 38322 & 5686 \\
\hline Eastern & 12452 & 12213 & $\begin{array}{c}-239 \text { (Import } \\
\text { from Bhutan } \\
1127 \mathrm{MW})\end{array}$ \\
\hline Western & 33024 & 28053 & -6229 \\
\hline Northeastern & 1367 & 1314 & -53 \\
\hline Total & 79479 & 79479 & \\
\hline
\end{tabular}

After the first disturbance, Northern Region grid could only extract power from the Eastern Region after the tripping of the Bina-Gwalior line which is the direct link from North to West. However, the link between the Western Region and the Eastern Region was still in operation, which caused power swing between Northern and Eastern Regions. Finally, the line between Eastern and Northern was cut out as it could not tolerate such destabilization, leaving the Northern Region grid in islanded mode. The next day, loads of the Northern Region extracted power from the Western-Eastern-Northern Region after losing the Bina-Gwalior line. However, this time the power swing centre is in the Eastern Region. Some parts of the Eastern Region and the entire Western Region grid were isolated from the NEW grid, which caused the power swing in the link from Northern Region to Eastern Region. Therefore, the Northern Region was separated from the NEW grid as well. These multiple faults led to the grid collapse. With the tripping of the generators in the Western Region to balance the power system frequency, loads in the Western Region did not suffer from the disturbances too much. Loads in Southern Region grid also met the demand requirement by extracting power from the Western Region.

\section{ModeLING}

In the paper, a simplified model was developed to simulate the grid behavior when the disturbance was started with DIgSILENT Power Factory software Package. Preliminary data reported by National Load Dispatch Centre, Power System Operation Corporation Limited at 18:30 $31^{\text {st }}$ of July, 2012 has been used in the model to investigate the dynamic performance under various scenarios that happened at 13:00 on the day [13].

Each part of the NEW grid involved in the blackout has been considered as an equivalent generation and load. The total load demand in each sector has been listed in Table 2. And it is not difficult to simply calculate that the Western Region load as $32612 \mathrm{MW}$. In addition, inter-regional exchange is also specified which is illustrated in Table 3 . The calculated total generation is shown in Table 4. Because the Northeastern Region is directly connected with Eastern Region grid, Eastern Region grid generation is assumed as the summation of both generation in Eastern Region grid and Northeastern Region grid.

Table 2. Load Demand met in the preliminary report

\begin{tabular}{|c|c|}
\hline Region & Demand (MW) \\
\hline Northern & 27320 \\
\hline Eastern & 12164 \\
\hline Northeastern & 1142 \\
\hline Total & 73238 \\
\hline
\end{tabular}

Figure 1 shows the model developed to represent the Indian grid, in which the two disturbances occurred, with DIgSILENT. The Northern Region and the Western Region are connected by, among others, a $400 \mathrm{kV}$ double circuit line between Agra and Gwalior. One circuit of this line has been out of service for up gradation to $765 \mathrm{kV}$. The Surge Impedance Loading (SIL) of the remaining circuit is $691 \mathrm{MW}$. There are other circuits between these two regions. Similarly the Eastern Region is connected to the Western Region as well as the Northern Region. The interconnections are shown in the figure. Some of the circuits connecting these regions were out of service prior to the disturbance. Line-tie parameters for model establishing are given in Table 5. Two lines are considered between the Northern Region and the Western Region. One represents the Agra-Gwalior line while the other line for the remaining interconnections. Both lines are assumed to have the same parameters. Each region was modeled for hydro and thermal generations and one lumped load.

The installed capacities of hydro and thermal generations in each region are assumed as follows: 
Northern Region:

10000MW Hydro generation and 13395MW Thermal generation;

Eastern Region:

3000MW Hydro generation and 10196MW Thermal generation;

Western Region:

6000MW Hydro generation and 30647MW Thermal generation allocated.

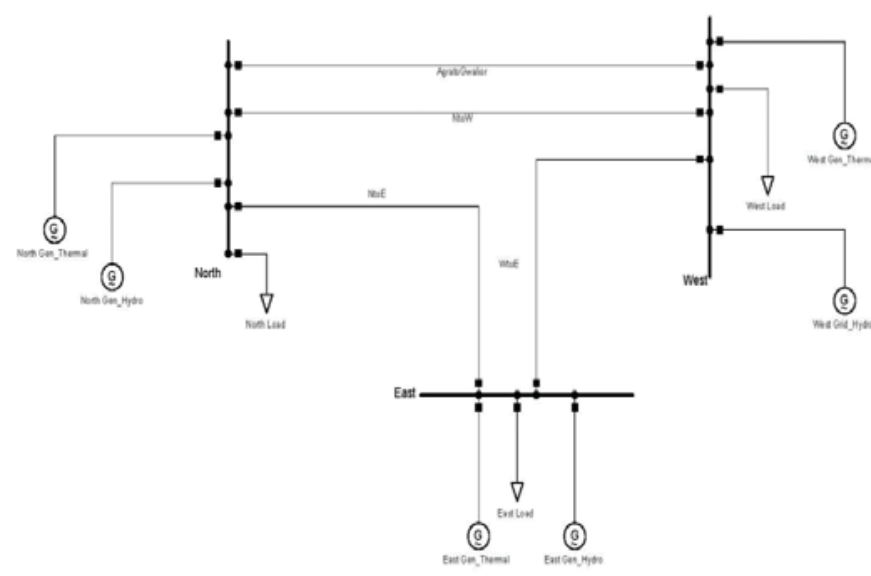

Fig. 1. Simplified India grid for disturbance investigation

Table 3. Inter-region Exchange in the India power grid.

\begin{tabular}{|c|c|c|c|}
\hline $\begin{array}{c}\text { Imported by Northern Region } \\
(\mathrm{MW})\end{array}$ & $\begin{array}{c}\text { Exported by Eastern Region } \\
(\mathrm{MW})\end{array}$ \\
\hline ER-NR & 1825 & ER-SR & 895 \\
\hline WR-NR & 2100 & ER-NR & 1825 \\
\hline & & ER-WR & -1935 \\
\hline & & ER-NER & 181 \\
\hline Total & 3925 & Total & 1066 \\
\hline
\end{tabular}

Table 4. Generation in each region

\begin{tabular}{|c|c|}
\hline Region & Generation (MW) \\
\hline Northern & 23395 \\
\hline Eastern & 13196 \\
\hline Western & 36647 \\
\hline
\end{tabular}

The parameters of the governors and the AVR have been taken as the default parameters available in the software. Also both hydro and thermal generation are coupled to the same bus to represent the total inflow of power from a particular region. The steady state power flow indicates that the lines between NR and WR are overloaded substantially while the lines between ER and NR and the lines between WR and ER are almost $100 \%$ loaded. The frequency of the system, however, seems to be within the permissible limits. The tripping of the Agra- Gwalior line caused an overloading of the other lines between NR and WR which resulted in the tripping of these lines. The tripping of the lines has been simulated by putting the Agra-Gwalior line out of service at $\mathrm{t}=60$ seconds and other lines between NR and WR at $\mathrm{t}=60.5$ seconds. This is to simulate the effect of cascade tripping of the lines between the North and the West. Figure 2 and Figure 3 respectively illustrate the frequency of Northern Region grid and changes in rotor angle between Northern Region and Western Region when the transmission lines linking these regions trip. Sensitivity analysis for investigating the grid robustness will be done in some cases below.

\section{CASE STUdy}

\section{Case 1 Change of generations in the north}

According to the background and the preliminary report [13], loads in the Northern Region grid are usually larger than the generation, Northern Region grid need to import power from other grids. This case is studying about behaviors of the entire grids when increasing the capacity investment or injecting more spinning reserve power into the Northern Region grid.

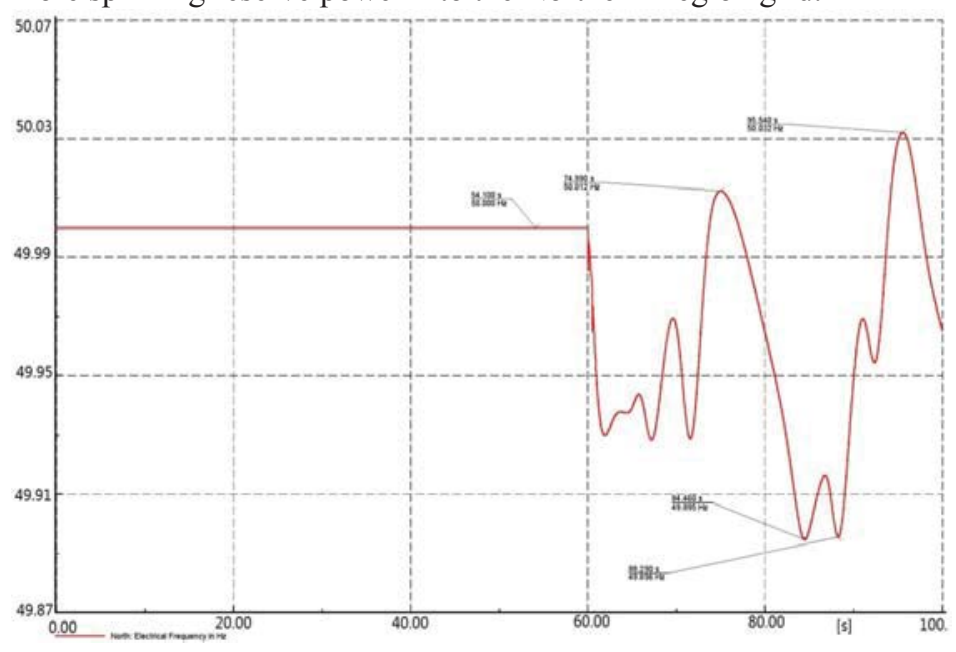

Fig. 2. Northern Region grid frequency

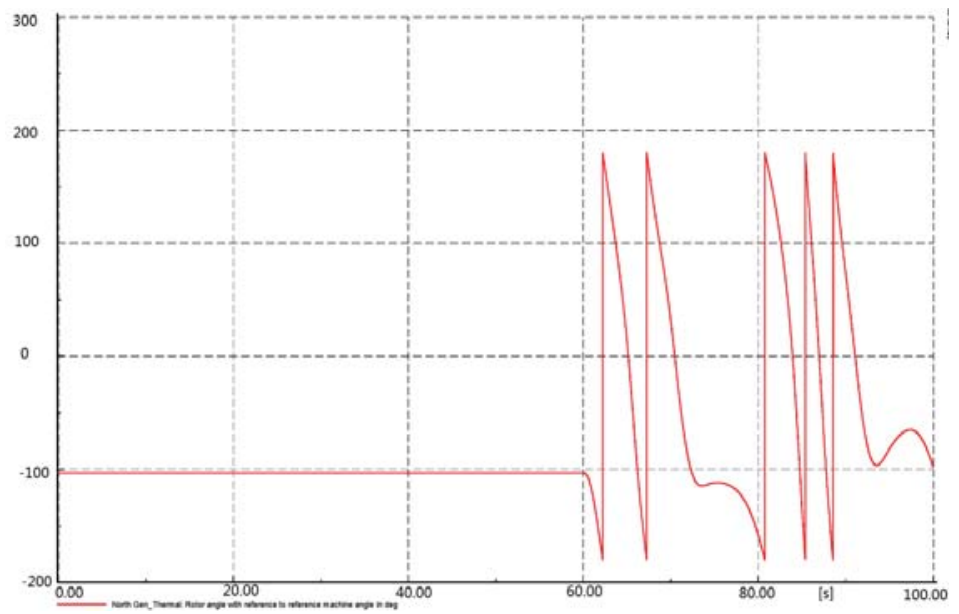

Fig. 3. Rotor angle of the Northern Region thermal generator refer to Western Region thermal generator 
Table 5. Parameters of the tie-line connecting between regions

\begin{tabular}{|c|c|c|c|}
\hline Regions & WR-NR & WR-ER & NR-ER \\
\hline $\begin{array}{c}\text { Voltage } \\
\text { level }\end{array}$ & $400 \mathrm{kV}$ & $400 \mathrm{kV}$ & $400 \mathrm{kV}$ \\
\hline $\begin{array}{c}\text { Line } \\
\text { reactance }\end{array}$ & $1.9623 \Omega / \mathrm{km}$ & $0.2381 \Omega / \mathrm{km}$ & $0.3333 \Omega$ \\
\hline $\begin{array}{c}\text { Line } \\
\text { resistance }\end{array}$ & $0.109 \Omega / \mathrm{km}$ & $0.013 \Omega / \mathrm{km}$ & $0.0185 \Omega / \mathrm{km}$ \\
\hline $\begin{array}{c}\text { Distance } \\
\begin{array}{c}\text { Surge } \\
\text { Impedance } \\
\text { Loading }\end{array}\end{array}$ & $118 \mathrm{~km}$ & $420 \mathrm{~km}$ & $300 \mathrm{~km}$ \\
\hline
\end{tabular}

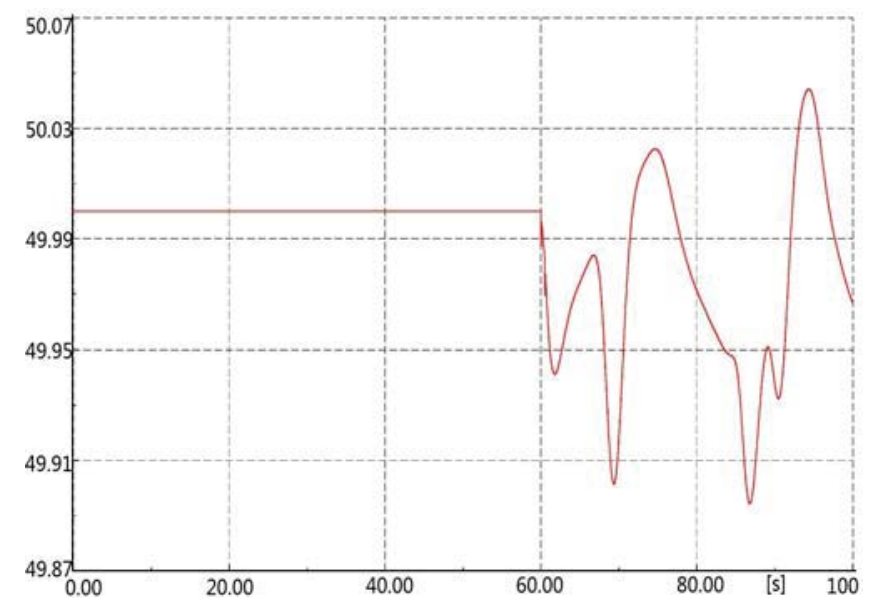

Fig. 4. (a)

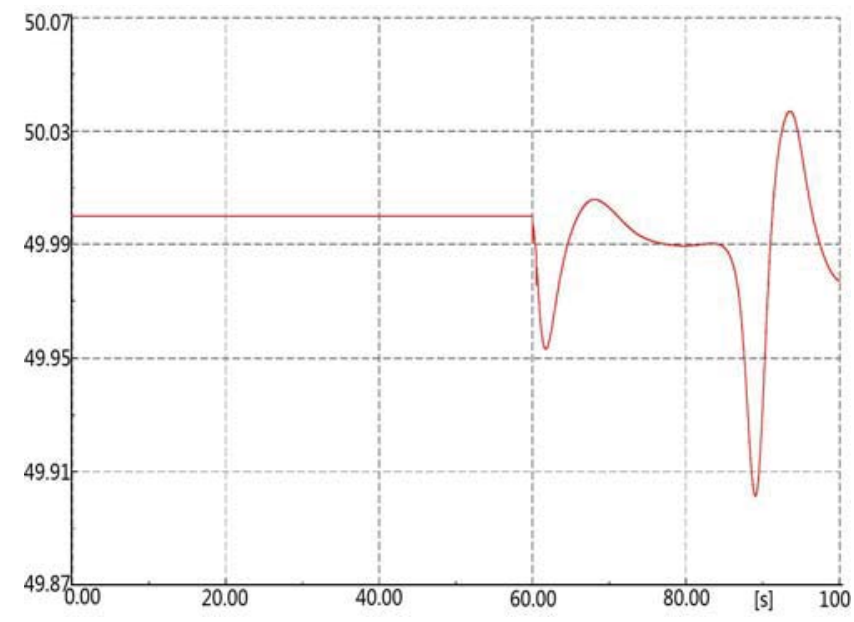

Fig. 4. (b)

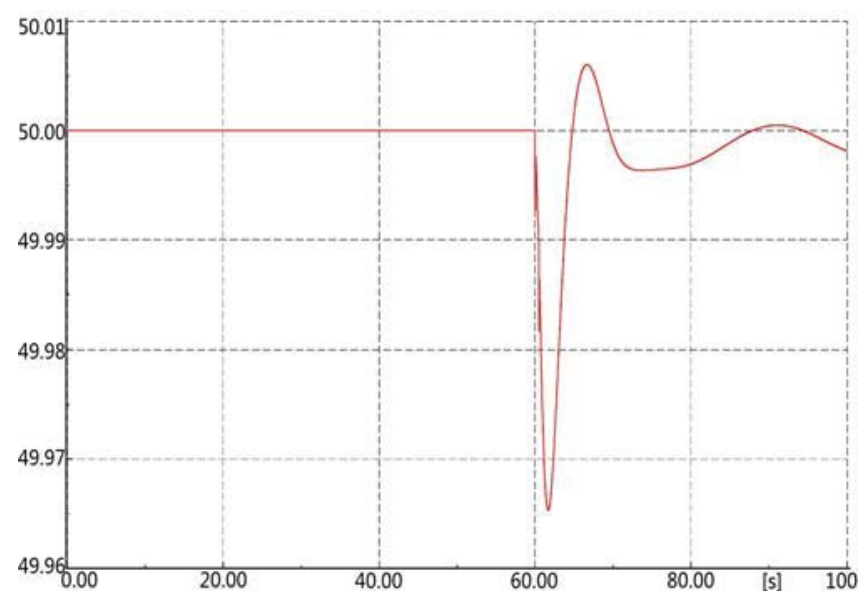

Fig. 4. (c)

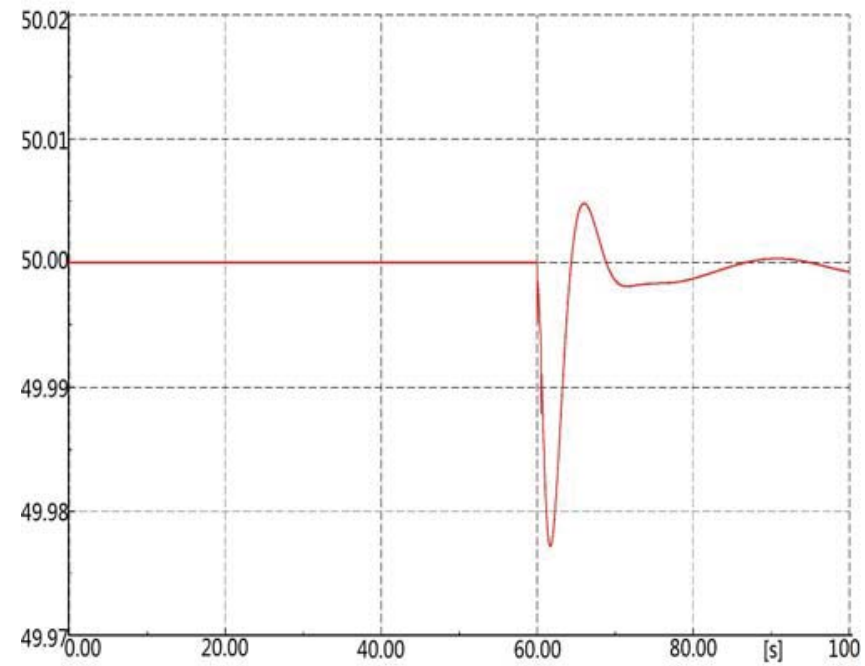

Fig. 4. (d)

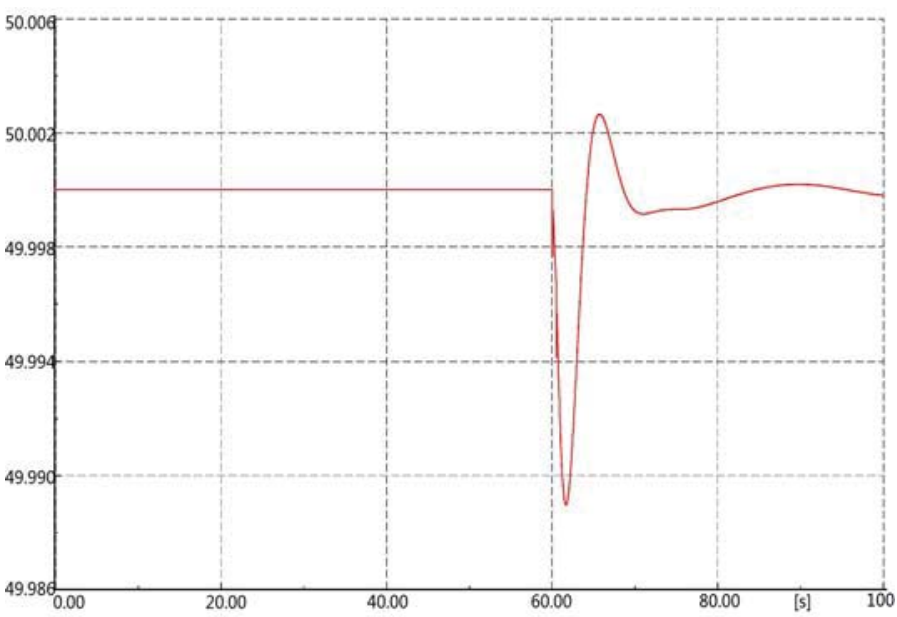

Fig. 4. (e)

Fig. 4. Changes of Northern Region grid frequency when (a) thermal generation in the northern region increased to $105 \%$; (b) thermal generation in the northern region increased to $110 \%$; (c) thermal generation in the northern region increased to $115 \%$; (d) thermal generation in the northern region increased to $120 \%$; (e) thermal generation in the northern region increased to $125 \%$. 


\section{A. Increasing the thermal generation power output}

The thermal power plant output power is increased from $100 \%$ to $125 \%$ with a step of $5 \%$. The results of the frequency measured in the Northern Region bus are shown in Figure 4. As can be seen in the diagram, Northern Region frequency fluctuation is getting smaller with the increased thermal generation output power. It is worthy noting that after the transmission line was out of service, frequency in the Northern Region can be recovered to the stable range when the thermal generation output power is higher than $115 \%$. Owing to the generation increasing in the Northern Region, it could meet such heavy load without importing energy from other grid.

Table 6. Maximum and minimum value of Northern Region frequency when hydro power is changing

\begin{tabular}{|l|l|l|}
\hline Hydro North & Minimum value & Maximum value \\
\hline $100 \%$ & $49.8946 \mathrm{~Hz}$ & $50.0321 \mathrm{~Hz}$ \\
\hline $105 \%$ & $49.902 \mathrm{~Hz}$ & $50.039 \mathrm{~Hz}$ \\
\hline $110 \%$ & $49.890 \mathrm{~Hz}$ & $50.042 \mathrm{~Hz}$ \\
\hline $115 \%$ & $49.956 \mathrm{~Hz}$ & $50.006 \mathrm{~Hz}$ \\
\hline $120 \%$ & $49.965 \mathrm{~Hz}$ & $50.006 \mathrm{~Hz}$ \\
\hline $125 \%$ & $49.974 \mathrm{~Hz}$ & $50.005 \mathrm{~Hz}$ \\
\hline
\end{tabular}

Table 7. Maximum and minimum value of rotor angle in the Northern Region when hydro power is changing

\begin{tabular}{|l|l|l|}
\hline Hydro North & Minimum value & Maximum value \\
\hline $100 \%$ & $-178.6 \mathrm{deg}$ & $179.5231 \mathrm{deg}$ \\
\hline $105 \%$ & $-179.915 \mathrm{deg}$ & $177.923 \mathrm{deg}$ \\
\hline $110 \%$ & $-179.973 \mathrm{deg}$ & $179.878 \mathrm{deg}$ \\
\hline $115 \%$ & $-164.864 \mathrm{deg}$ & $-56.879 \mathrm{deg}$ \\
\hline $120 \%$ & $-116.074 \mathrm{deg}$ & $-46.907 \mathrm{deg}$ \\
\hline $125 \%$ & $-84.613 \mathrm{deg}$ & $-37.685 \mathrm{deg}$ \\
\hline
\end{tabular}

\section{B. Increasing the hydro power output}

The hydro generator output is increased from $100 \%$ to $125 \%$, maximum and minimum values of Northern Region frequency and rotor angle are recorded in Tables 6 and 7. With the increasing capacity injected to the system, frequency is much more stable when the line Agra-Gwailor and Northern to Western line are out of service. Rotor angle deviation between north bus and west bus is getting smaller. Differences between minimum and maximum power from east to north is narrowing.

\section{Case 2 Wind generation investment in Western Region}

This case is to study the frequency, rotor angle difference and power imported from Eastern grid to Northern Region. In this case, the Western Region grid has wind farms with asynchronous machines. The wind farm Capacity is set in percentages of the output power generated by the thermal power plants in the Western Region grid. Table 8 gives information on maximum and minimum value frequency, imported power from east to north, and rotor angle difference with wind penetration level increased from $10 \%$ to $26 \%$. In accordance with the data recorded in the table, frequency fluctuation becomes smaller and smaller. When wind penetration level is around $20 \%$, the frequency cannot even reach $50 \mathrm{~Hz}$ after breaking the line linking Northern Region to Western Region.

Imported power from North to East is smaller before the occurrence of the disturbance, because Northern Region could import power from Western Region directly. After the disturbance, the Northern Region could only obtain power from Eastern grid. The power from Northern to Eastern increases suddenly to an extremely high level to meet the demand in the Northern Region. Generators go out of step at $\mathrm{t}=70$ seconds, and the rotor angle becomes smaller but fluctuates strongly after disturbance. It is obviously stated that with wind penetration getting large in the Western Region grid, Northern Region grid cannot effectively extract power from the Eastern and Western Region grid.

\section{DISCUSSIONS AND CONCLUSIONS}

The paper gives a brief event sequence of the disturbance that occurred on $30^{\text {th }}$ and $31^{\text {st }}$ of July 2012. Reasons for the disturbance have been discussed. grid infrastructure, which is applying both $\mathrm{AC}$ and $\mathrm{DC}$ transmission lines to connect regions, is one of the main problems for these disturbances. The generation production is dependent too much on the weather condition, and the power cannot be restored within a short time. Some sensitivity analysis has been done to investigate the level of the disturbance affected the grid when power generated in the North and wind penetration level in the Western Region grid is increased. Increasing the power output in the Northern Region is a simple solution when the load is increased in the Northern Region grid as then the transmission line linking the regions is not overloaded. Wind generation in the Western Region grid cannot supply enough energy from the Western-Eastern-Northern area when the lines between Northern Region and Western Region are out of service. It can be foreseen that a coordinated dispatch schedule is essential for a secure electricity supply. From the blackout, it also suggests that increasing rate of generation capacity is lacking behind the economy development rate. It is important to plan the electricity infrastructures at least few years in advance. 
Table 8. Maximum and Minimum value of frequency, power from North to East, and rotor angle difference when wind penetration is getting large in the Western Region

\begin{tabular}{|c|c|c|c|c|c|c|c|c|c|}
\hline \multirow{2}{*}{$\begin{array}{l}\text { Wind generation } \\
\text { (\% of Western } \\
\text { Region thermal } \\
\text { generation) }\end{array}$} & \multicolumn{3}{|c|}{ Frequency } & \multicolumn{3}{|c|}{ Northern grid to Eastern grid power } & \multicolumn{3}{|c|}{ Rotor angle difference } \\
\hline & Orig & $\min$ & $\max$ & Orig & $\min$ & $\max$ & Orig & $\min$ & $\max$ \\
\hline $10 \%$ & 50 & 49.737 & 50.026 & -1722.354 & -2577.435 & 2884.222 & -100.644 & -179.727 & 179.941 \\
\hline $12 \%$ & 50 & 49.742 & 50.043 & -1722.345 & -2577.467 & 2880.186 & -100.177 & -179.909 & 179.769 \\
\hline $14 \%$ & 50 & 49.745 & 50.014 & -1722.337 & -2577.489 & 2880.589 & --99.703 & -179.988 & 179.968 \\
\hline $16 \%$ & 50 & 49.746 & 50.002 & -1722.327 & -2577.534 & 2880.229 & -99.220 & -179.950 & 179.979 \\
\hline $18 \%$ & 50 & 49.746 & 49.994 & -1722.319 & -2577.565 & 2879.119 & -98.729 & -179.843 & 179.914 \\
\hline $20 \%$ & 50 & 49.744 & 49.991 & -1722.310 & -2577.575 & 2877.809 & -98.231 & -179.909 & 179.888 \\
\hline $22 \%$ & 50 & 49.740 & 49.992 & -1722.300 & -2577.620 & 2876.276 & -97.725 & -179.859 & 179.981 \\
\hline $24 \%$ & 50 & 49.738 & 50.002 & -1722.292 & -2577.640 & 2874.505 & -97.209 & -179.985 & 179.901 \\
\hline $26 \%$ & 50 & 49.776 & 50.035 & -1722.283 & -2577.651 & 2872.762 & -97.687 & -179.993 & 179.993 \\
\hline
\end{tabular}

\section{REFERENCES}

1. http://www.usatoday.com/news/world/story/2012-07$31 /$ india-power-outage/56600520/1, visited on 16 th August, 2012

2. http://www.guardian.co.uk/world/2012/jul/31/indiablackout-electricity-power-cuts, visited on 16th August, 2012

3. http://washpost.bloomberg.com/Story?docId=1376M7YDKA0YHQ0X0179TK1GQCDQF2C5AQ5A383U7GQR, visited on 16th August, 2012

4. http://www.thehindubusinessline.in/2006/08/17/stories/20 06081704790100.htm, visited on 16th August, 2012

5. http://www.indianembassythimphu.bt/mega.html, visited on 16th August, 2012

6. http://www.thehindu.com/news/national/article3702075.e ce visited on 16th August, 2012

7. "Report of the Enquiry Committee on Grid Disturbance in Northern Region on 30th July 2012 and in Northern, Eastern \& North-eastern Region on 31st July 2012", http://www.cea.nic.in /reports/articles/god/grid_disturbanc e_report.pdf, visited on 16th August, 2012

8. "ABC of ABT, A Primer on Availability Tariff", http://www.nldc.in/docs/abc_abt.pdf, visited on 16th August, 2012

9. "Loading of Extra High Voltage (EHV) transmission elements on the network and its impact on the grid security",

http://www.nrldc.in/flasher/Website_NLDC_TTC_calcula tions_SIL01Aug2012.pdf, visited on 1st of September, 2012
10. http://spectrum.ieee.org/energywise/energy/the-smartergrid/disappointing-monsoon-season-wreaks-havoc-withindias-grid, visited on16th August, 2012

11. PowerFactory, DIgSILENT 14.1

12. "Operation Performance Report for the Month of July 2012", http:/www.nldc.in/NLDC/monthlyreport/July\%202012\% 20Monthly\%20Report\%20.pdf, visited on 16th August, 2012

13. http://nldc.in/Flasher/Flash\%20Report_NLDC_Grid $\% 20$ Disturbance\%20in\%20Northern\%20Region_31072012.pd f, Preliminary Data reported by National Load Dispatch Centre at 18:30 31st of July, visited on 15th August, 2012 